\title{
Dor Pós-amputação - Abordagem Terapêutica
}

\author{
Hatsue Sakamoto*
}

\section{RESUMO}

O tratamento da dor no coto e/ou dor fantasma após a amputação é uma tarefa difícil, pois desconhecemos a fisiopatologia e as alterações neuroquímicas que ocorrem no sistema nervoso. Ele depende do tipo de dor, o grau de severidade e o quanto incapacita o paciente; geralmente o tratamento se baseia em técnicas não invasivas por que de acordo com vários estudos, as técnicas invasivas são pouco eficazes. Além disso, qualquer intervenção cirúrgica no sistema nervoso periférico ou central, nos casos de dor por deaferentação, pode incrementar a deaferentação aumentando o risco de persistência da dor. O programa reabilitacional é a base do tratamento da dor.pós-amputação.

\section{SUMMARY}

The treatment of stump/phantom pain following amputation is a difficult task because of unknown patho-physiology and neurochemical changes in nervous system. It depends on the type of pain, its severity and to what extend pain incapacitates the patient. In general, treatment should be based on non invasive techniques because according to the most studies of invasive techniques it results poorly. More over surgery on the peripheral or central nervous system in cases of deafferentation pain always implicates further deafferentation and there by provides an increased risk for persistent pain. Rehabilitation program is the base of the treatment in stump/phantom pain.

\section{Introdução}

O termo "dor pós-amputação" abrange basicamente dois aspectos:

\section{Dor no Coto de Amputação}

Sua incidência varia de 13\% (Cronholm, 1951) a 71\% (Kroinick e Thoden, 1976). Aparece geralmente nas primeiras semanas a despeito de uma cicatriz com boa evolução; em caráter de punhalada ou choque; desencadeada facilmente por estimulação do coto através de percussão ou pressão. Sua evolução é variável e, segundo levantamentos de Jensen e Rosmussem persistem em $22 \%$ e $21 \%$ dos pacientes, 6 meses e 2 anos após, a amputação.

Faz parte do fenômeno doloroso movimentos espontâneos do coto conhecidos como coréia do coto, tique doloroso.

Temos uma variante de dor estudada por Sunderloand (1978) que denominou de "nerve storm", a qual consiste de ataques dolorosos; geralmente com dois dias de duração; agudos, que inicia, termina e declina minuto a minuto. Evolui com atrofia do coto, que se apresenta frio, cronótico e sudoreico.

\section{Dor Fantasma}

Trata-se de um fenômeno muito estudado, mas, ainda pouco conhecido, onde o paciente tem a experiência de uma sensação

\footnotetext{
* Médica Fisiatra da Divisão de Medicina de Reabilitação do Hospital das Clínicas da Faculdade
} de Medicina da Universidade de São Paulo. 
desagradável no membro ou parte deste, cirurgicamente removido. A incidência varia de $2 \%$ (Abramson e Zeibel, 1981) até 97\% (Pitres, 1897) a dor aparece geralmente na $1^{\text {a }}$ semana após a amputação e persiste por meses ou até anos. Normalmente se localiza distalmente no membro fantasma (dedos, pés, panturrilha), é referido como uma sensação de aperto, "unha pendendo na polpa do dedo".

Embora se tenha estudos prospectivos que possibilitem definir melhor os vários aspectos da dor fantasma, parece que a persistência de dor severa ocorre em aproximadamente 5 a $10 \%$ dos amputados com dor fantasma.

\section{Mecanismos Etiológicos e Fisiopatológicos}

Embora muito estudado permanece desconhecido. Pelas observações e experiências conseguimos distinguir um mecanismo periférico, espinhal e supra-espinhal.

Periférico, foi observado por Nyström e Hagborth (1981) que fizeram registros com microeletrodos de um nervo trans-sucronado a percussão de neuromas induz atividade nas fibras aferentes (provavelmente fibras do tipo C) a qual está associada com o aumento da dor fantasma.

$\mathrm{Na}$ evolução da amputação encontramos no coto uma reinervação caótica com formação de sítios ectópicos de excitação e sinapses anormais que alteram a sensibilidade e a forma sensitiva do coto ( p.ex. alodinia).

Observações clínicas sugerem que mecanismos periféricos participem no fenômeno de dor fantasma/membro fantasma.

1) Pode se modular a sensação de membro fantasma pela manipulação do coto (Cronholm, 1951; Carlen et al, 1978; Jensen et al, 1983).

2) A anestesia local do coto faz com que desapareça temporariamente a sensação de membro fantasma (Sunderland, 1978).

3) A revisão cirúrgica e remoção de neuromas reduz temporariamente a dor.

4) A dor fantasma é significativamente mais freqüente em pacientes com dor no coto do que naqueles que não a apresentam. (Jensen et al, 1983).

5) A alteração da sensibilidade cutânea do coto é um aspecto comum. (Jensen et al, 1985).

6) Alterações no fluxo sangüíneo do coto levam a alterações na percepção do membro fantasma (Shermon, 1984).

\section{Medula Espinhal}

Achados clínicos sugerem que a ME tenha atuação na modulação da dor/membro fantasma:

- Lesão da ME e avulsão de raízes do plexo braquial estão às vezes associados com dor de mesmas características e localização observadas nos pacientes amputados com dor fantasma.

- Foram observados alguns casos de pacientes com hérnia discal, que evoluíram com mielopatia, fenômenos idênticos ao do membro fantasma, que regrediram após a recuperação da mielopatia.

Alguns trabalhos experimentais mostraram que ocorrem alterações morfológicas, fisiológicas e neuroquímicas no corno posterior da ME após lesão do nervo periférico, que incluem atrofia do terminal aferente primário com perda de vários peptídeos; alteração na depolarização do aferente primário; inibição e expansão do território receptor periférico. Todas estas alterações fazem com que os neurônios do corno posterior que tenham perdido o input aferente normal comecem a responder aos neurônios aferentes próximos, que estão intactos.

A explicação possível é que os neurônios do corno póstero-medial, com territórios receptores na pele, localizados em partes distais do membro apresentem atividade espontânea do membro, o que resulta em que estas células possam se dirigir para áreas localizadas mais proximalmente.

Estudos mais recentes mostraram depleção de substância P no corno posterior de animais após a secção do nervo periférico ou de raízes dorsais.

Apesar de todos os achados e estudos feitos não se sabe com precisão o mecanismo medular na modulação da dor fantasma.

\section{Mecanismos Supra-espinhais}

Também baseados em observações e experiências sabemos que a imagem do membro fantasma é integrada no cérebro, onde estruturas talâmicas e corticais possivelmente modulam a dor fantasma e a sensação do membro fantasma.

- Após a lesão do hemisfério direito observouse o desaparecimento do membro fantasma esquerdo. (Head e Holmes, 1915).

- A lesão cortical, principalmente da região parietal pode levar ao desaparecimento do membro fantasma contralateral. (Appenzeller e Bicknell, 1969).

- A estimulação elétrica da região porvo celular do núcleo ventral póstero-lateral do tálamo reduz a dor fantasma e a sensação do membro fantasma (Merienne e Mazard, 1981).

-Estudos eletrofisiológicos recentes documentaram a existência de neurônios nociceptivos específicos no córtex cerebral.

Os meios de transmissão do sistema nociceptivo, com seus circuitos modulatórios que aumentam a projeção para a substância rostral nas vias ascendentes torna difícil separar qual o provável mecanismo supra-espinhal envolvido no desencadeamento e modulação do fenômeno do membro fantasma.

\section{Tratamento}


A abordagem terapêutica da dor crônica pósamputação é complexa e árdua exatamente porque não conhecemos os mecanismos fisiopatológicos e neuroquímicos envolvidos, e porque temos fatores individuais psicoemocionais e sociais que interferem de forma definitiva na evolução da dor fantasma e que são de difícil solução.

Segundo levantamentos de Sherman e Sherman (1985) apenas 20\% dos pacientes com dor fantasma recebem algum tipo de tratamento. Dos pacientes tratados raramente obtemos uma taxa de sucesso acima da resposta placebo que é de $30 \%$.

A seguir descrevemos o tratamento que se divide basicamente em técnicas não invasivas e invasivas. Geralmente optamos pelo tratamento não invasivo pois a intervenção cirúrgica no sistema nervoso central ou periférico nos casos de dor por deaferentação pode incrementar a cleoferentação e aumentar o risco de persistência da dor.

\section{Técnicas não Invasivas}

\section{Abordagem Fisiátrica/Fisioterápica}

O tratamento começa logo no pré-operatório quando tentamos obter condições que possibilitem uma boa evolução pós-cirúrgica. Nesta fase orientamos exercícios visando a manutenção de uma boa amplitude de movimento da articulação proximal à amputação prevista, exercícios para manter o trofismo muscular; tendo em mente a protetização.

No pós-operatório imediato devemos orientar o serviço de enfermagem quanto ao posicionamento do coto que deve estar sempre em posição funcional. Deve ser evitado o uso dos tão comuns coxins e travesseiros elevando o coto, pois leva a retrações em flexão impossibilitando muitas vezes uma boa protetização com grande prejuízo para o paciente pois a recuperação da amplitude do movimento nem sempre é possível.

Nesta fase iniciamos também a massagem para drenagem de edema o que viabiliza um coto com menos fibrose e melhores condições tróficas, o que favorece uma boa cicatrização. O enfaixamento do coto com faixas elásticas também é importante para um bom resultado. Ele é feito no sentido distal proximal, com uma tensão maior na porção distal do coto e que diminui progressivamente no sentido centrípeto, dando ao coto uma forma crônica. Concomitantemente o paciente mantém os mesmos exercícios para manter a amplitude do movimento da articulação proximal à amputação; e exercícios para manter o trofismo muscular. Assim que as condições clínicas do paciente permitirem, iniciase a transferência de peso corporal para o coto.

Quando tentamos obter um coto ideal para amputação, automaticamente afastamos alguns fatores que podem ser determinantes para o aparecimento da dor no coto e/ou dor fantasma.
O tratamento do paciente com dor durante a evolução pós-amputação compreende o uso de várias técnicas fisioterápicas e/ou meios físicos. Normalmente associamos uma técnica / cinesioterapia com meio físico.

Calor profundo: MO, OC, US (associa o calor profundo com uma "massagem" que é obtida quando pressionamos e desligamos o cabeçote sobre o coto). Promove vaso-dilatação melhorando as condições circulatórias, com maior drenagem de cininas e melhor trofismo dos tecidos, evitando zonas maiores de fibrose e aderências.

TENS - Estimulação elétrica transcutânea do nervo. Estimula as fibras aferentes A delta e C, que através do corno posterior da medula, ativa os circuitos inibitórios da dor no local estimulado. Obtemos uma boa analgesia com essa técnica.

STEREODYNATOR- Associa a sucção intermitente com uma corrente elétrica que promove analgesia. Com esse meio obtemos melhor circulação local e analgesia com bons resultados também.

CRIOTERAPIA - Reduz o espasmo muscular quebrando o círculo vicioso: espasmo - dor espasmo.

Geralmente optamos por esse meio quando existe edema.

HIDROTERAPIA - A água exerce efeitos psíquicos positivos, reduz o espasmo muscular e possibilita uma ampla gama de exercícios que normalmente não conseguimos nos exercícios de solo com pacientes amputados. Melhoramos as condições cardiopulmonares, o equilíbrio e a força muscular.

DESSENSIBILIZAÇÃO DO COTO - Através de estímulos mecânicos como apoio interminantemente do coto sobre uma almofada contendo bolas de gude ou grãos de cereais.

CINESIOTERAPIA - Através de exercícios passivos, ativos assistidos, ativos, ativos resistidos mantemos a amplitude do movimento da articulação proximal à amputação, melhoramos o trofismo dos tecidos do coto e obtermos uma musculatura adequada para uma boa protetização. Evitando a imobilidade do membro conseguimos prevenir o aparecimento ou melhorar o nível de dor.

A técnica utilizada na maioria das vezes não segue uma norma pois existem diferenças individuais de resposta o que exige do terapeuta um trabalho de tentativa e erro até chegar ao que é mais adequado para cada amputado. E cada amputado, no decorrer do tratamento, pela própria evolução clínica passa a exigir diferentes técnicas conforme o estágio em que se encontre.

\section{Abordagem Medicamentosa}

Até o momento não existe uma droga que seja específica para o tratamento da dor no amputado. 
O que observamos são respostas que variam de indivíduo para indivíduo a determinadas drogas que atuam no controle da dor através de mecanismos ainda não conhecidos.

- Carbamazepina 200 a 1200 mg/dia fracionadas em várias doses.

- Analgésicos associados com clorpromazina. Os analgésicos são dados nas doses usuais e a clorpromazine é dada numa dosagem que vai de $25 \mathrm{mg}$ até $500 \mathrm{mg}$ ao dia.

- Antidepressivos como, por exemplo, a amitriptilina em doses que vão de 25 a 150 mg/dia

- Opióides como a morfina também são usados com certo sucesso no controle da dor. A dose necessária pode ser de $5 \mathrm{mg}$ até $1 \mathrm{~g}$ a cada 4 horas.

Qualquer que seja o medicamento sempre administramos a menor dose que tenha um efeito terapêutico no controle da dor.

\section{Técnicas Invasivas}

- Revisão do coto: Está limitado a poucos casos com patologia incidente do coto (coto ósseo inadequado, retrações, etc.). Não se faz revisão cirúrgica para remover neuromas visto que isso leva à formação de novos bulbos.

- Neurotomia/Rizotomia: técnica praticamente abolida pelos poucos resultados obtidos.

- Simpatectomia Kalio (1950): observou-se um efeito imediato em $43 \%$ de pacientes, mas, após $6 \mathrm{~m}$, $80 \%$ desses pacientes tiveram recorrência do quadro doloroso. $\mathrm{O}$ uso de guanetidina na simpotectomia química ainda não está claro, mas, pelas respostas obtidas poderá ser de grande valor no tratamento da dor.

- Lesão da zona de entrada da raiz dorsal: Soris et al, (1985) estudou 22 pacientes com dor no coto e dor fantasma que se submeteram a essa intervenção e fez o seguimento por $6 \mathrm{~m}$ a 4 anos após a cirurgia e observou que apenas $36 \%$ desses pacientes obtiveram algum alívio da dor.

- Estimulação da ME, Kroinick et al (1980): implantou marca-passos subcutâneos para estimular a ME em 64 pacientes com dor pósamputação obtendo uma redução de 50 a $100 \%$ no nível de dor em $45 \%$ dos pacientes e de 25 a $50 \%$ em $11 \%$ dos pacientes. Num levantamento, após 5 anos, $23 \%$ dos pacientes ainda mantinham um alívio de 50 a $100 \%$ da dor.

- Estimulação cerebral: Mundinger e Salomão (1980) trataram 32 pacientes com dor talâmica, neuralgia pós herpética, anestesia dolorosa e dor fantasma com esta técnica e obtiveram um alívio de mais de $50 \%$ da dor em $53 \%$ dos pacientes tratados.

- Cordotomia: Praticamente não se faz mais pelos resultados insatisfatórios obtidos.

Prevenção: Boch et al (1988) observou que o uso de bloqueio epidural lombar com bupivocaine e/ou morfina durante 03 dias antes da amputação reduz a incidência de dor fantasma no primeiro ano após a amputação.

\section{Conclusão}

O tratamento da dor fantasma e/ou dor no coto é uma tarefa árdua visto que não são conhecidas as alterações fisiológicas e neuroquímicas que ocorrem após a amputação.

Sempre optamos em primeiro lugar pelas técnicas não invasivas, pois como mostra a experiência, as técnicas invasivas ainda têm resultados insatisfatórios, além do que submetemos o paciente a uma nova agressão.

Qualquer que seja o método adotado sempre temos por base o tratamento fisiátrico/ fisioterápico, pois este visa um coto sadio, o que é o primeiro passo para uma boa evolução clínica.

\section{Referências Bibliográficas}

1. Abramson, A.S.; Zeibel, A. 1981. The phantom phenomenon: its use and desuse. Bulletin of the New York Academy of Medicine 57: 99-112.

2. Bors, E. 1951 phantom limbs of patients with spinal cord injury. Archives of Neurology and Psychiatry 66: 619-631.

3. Brown W. A. 1968. Postampritation phantom limb pain. Diseases of the nervous system 29. 301-306.

4. Carabelli, R. A.; Kellermon W. C. 1985. Phantom limb pain, relief by application of TENS to contralateral extremity. Archives of Phisycal Medicine and Rehabilitation 66: 466-477.

5. Gutierrez Mahoney, C. G. 1948. The tretament of painful phantom limb. A follow up study. Surgical clinics of North America 28: 481-483.

6. Gillis, L. 1964. The management of the painful amputation stump and a new theory for the phantom phenomena. British Journal of Surgery 51: 87-95.

7. Hermann, L. G.; Gibbs E. W. 1945. Phantom limb pain. American Journal of Surgery 67: 168-180.

8 Jensen; T. S.; Krebs, B.; Nielsen J, Rasmussen P. 1993. Phantom limb, phantom pain and stump pain in amputees during the first 6 months following limb amputation. Pain 17: 243-256.

9. Jensen-Rosmussen. 1984. Phantom pain and related phenomena after amputation. Textbook of pain 36: 508-521.

10. Melzak, R. 1971. Phantom limb pain: implication for treatment of pathological pain. Anesthesiology 35: 409-419.

11. Parkes, C. M. 1973. Factors determining the persistence of phantom pain in the amputee. Journal of Psychosomatic Research 17: 97-108.

12. Saris, S. C.; lacono, R. P.; Nashold, B. S. Jr. 1985. Dorsal root entry zone lesions for post amputation pain. Journal of Neuro surgery 62: 72-76.

13. Sherman, R. A.: Sherman C. J. 1985. A comparison of phantom sensations among amputees whose amputations were of. Civilian and military origins. Pain 21: 91-97.

14. Urban, B. J.; France, R. D.; Steinberger E. K.; Acoot, D. L.; Maltbie, A. A. 1986. Long term use of. Narcotec/ antidepressant medication in the management of phantom limb pain. Pain 24: 191-196. 